\title{
Developing student research capability for a 'post-truth' world: three challenges for integrating research across taught programmes
}

\section{Dr Gwyneth Hughes}

\section{UCL, Institute of Education, University College London}

\begin{abstract}
Research-based learning in taught courses develops the skills needed to judge knowledge sources and think critically in a post-truth world. In viewing research skills as threshold concepts, the paper argues that transforming a student cannot be a one-off event. Research capacity must build over a programme and this requires coherent research skill development and assessment that is progressive (ipsative). A study of five programmes each with a different design of research 'throughline' showed that such integrated research based learning generates three challenges. Firstly, conceptualising the research skills and progression is not easy. Secondly, the accumulation and enrichment of research skills is not readily visible to students. Finally, providing a clear support system across the programme is not straightforward. The paper concludes that these challenges need to be addressed if the potential of research-based education to enable future citizens to interrogate populist claims and reject misinformation is to be realised.
\end{abstract}

Keywords research-based learning, research development, undergraduate research, threshold concepts, ipsative assessment

\section{Introduction}

In an age where appeals to emotion and personal beliefs hold sway over expertise and academic values, an ability to interrogate received knowledge using robust evidence becomes increasingly important (Speed and Mannion 2017). This paper supports a view that taking part in open research/enquiry has the potential to equip learners at all higher education levels to develop the criticality they will need for living and working in such a 'post-truth' world. 
Such criticality might mean moving away from treating populist opinions as facts, being able to question data sources, recognise bias and use these attributes to make judgements about knowledge claims.

Research-based education has become a part of undergraduate as well as postgraduate learning where 'research' is not necessarily about new knowledge production but includes questioning, enquiry and problem solving as part of a research-teaching nexus (Healey and Jenkins 2009; Spronken-Smith and Walker 2010). Levy and Petrulis (2012) helpfully distinguish between research as gathering information, and research as development of student ideas, and propose that research/enquiry can span a spectrum from teacher-framed to student-framed questions with varying degrees of open-endedness. But, beyond defining research/enquiry-based learning, there is the question of how research capability can be taught or developed so that the supposed learning benefits are realised. With a need to empower $21^{\text {st }}$ century students to make appropriate judgements about the quality and accuracy of the deluge of information and opinion they receive online, developing their questioning abilities and critical thinking through some form of research/enquiry becomes more and more urgent.

Research development is not new and it has become widely acknowledged that postgraduate researchers require 'research training' in the research methods of the discipline and other generic skills, increasingly to support an employability agenda. For more than a decade in the UK, 'Robert's' money available to institutions for doctoral research training has encouraged structured provision of research skills and produced the Vitae researcher development framework (Hodge 2010). Many funders of doctorates now require the provision of research training. However, embedding clearly defined research development and planning is not straightforward and, with the possible exception of taught doctorates and research-based Masters, the responsibility for managing and assessing research development 
is largely left to the individual student and supervisor. The extension of research-based learning to undergraduates, who may not have the autonomy expected of a postgraduate, and who will not formally continue as academic researchers, throws the problems of defining research skills and assessing the acquisition of skills into sharper relief.

There are two main approaches to developing research skills or capabilities that could apply to undergraduates as well as postgraduates. One option is the establishment of on-going and discrete research skills support programmes which may be required or voluntary. Another option is for research development to be embedded in a taught programme. However, as with postgraduate researchers, learners on taught undergraduate and masters programmes must develop research capability over time and in modular taught programmes it is not immediately clear how research skills and attributes are identified and accumulate. Fung (2017) has suggested that a key dimension of research-based education is designing a 'throughline' of research activity that provides a structure so that burgeoning research capability can be supported and assessed throughout a programme.

But curriculum design on paper does not easily translate into practice; students may struggle with certain aspects of research/enquiry such as criticality (Rattray 2017) or open-ended enquiry (Levy and Petrulis 2012). This paper applies the work of Meyer and Land (2003) on threshold concepts and troublesome knowledge to research skills development that is of particular relevance in a post-truth age. Assessment of research development will also need to be longitudinal, and Hughes $(2011,2014,2017)$ has proposed that ipsative assessment, that is assessment of a learning journey, motivates students, especially those who are struggling, but is not straightforward to implement.

This paper examines the practicalities for both designing and running an effective research throughline for a taught programme whether at undergraduate or Masters level. Three 
challenges emerged from a study of five programmes which have each responded to a 'Connected Curriculum' initiative to develop research throughlines at a research-intensive university (Fung 2017). These challenges are: conceptualising disciplinary and generic research skills and identifying threshold concepts; ensuring that the accumulation and enrichment of research skills is recorded throughout the programme; supporting the research development of all students, not only those who may continue as researchers. Addressing these challenges is essential for a critical and enquiring capacity to then be transferrable to other aspects of current and future life. The paper concludes that while research-based learning has the potential to equip all students with skills for a post-truth world, putting this into practice will need some careful planning.

\section{Research-based learning in taught undergraduate programmes}

That university education is informed by research is not disputed, even if teachers are not necessarily active researchers in the Humboldtian tradition (Harland 2016). Research-based education is becoming a goal for many universities, where students are not only researchinformed, but also become researchers. But, the student benefits of taking part in research are less clearly established.

Despite limited evidence, undertaking research or enquiry in higher education is widely assumed to improve student motivation, thinking ability and employability, through for example team working and communication skills, (Waite and Davis 2006; Craney et al. 2011; Taraban and Logue 2012) and thinking like a scientist (Seymour et al. 2004). But, in the ideology of the positive effects of research-based learning, it is unclear which students gain from research/enquiry based learning. It may be that only the stronger students benefit and develop a research mind-set, while others may not appreciate the transferability of skills, and those with lower grades may even be demotivated by research projects (Taraban and Logue 
2012). Supervisors may be motivated by encouraging targeted students to continue with a research degree, or by getting ideas for their own research, rather than by widening their research community to include all students (Brewer et. al. 2012; Ng and Pemberton 2013).

There might be several reasons why some students appear not to be gaining much from research activity. Many research skills are also generic skills such as team-working, communication and time-management, but others may be particularly associated with research/enquiry such as asking good questions, data analysis, critical interpretation and judging the quality of evidence and these are of particular relevance in a post-truth world so that students will know how to challenge unsubstantiated beliefs and develop their own perspectives. Such research skills are also difficult to capture and monitor over time, and can provide particular challenges for students as they may encounter threshold concepts - places where many students get stuck and are unable to progress (Meyer and Land 2003, 2005; Rattray 2017; Kiley 2009).

Research skills and threshold concepts

Land and Meyer $(2003,1)$ first defined threshold concepts as follows:

A threshold concept can be considered as akin to a portal, opening up a new and previously inaccessible way of thinking about something. It represents a transformed way of understanding, or interpreting, or viewing something without which the learner cannot progress.

Key here is that threshold concepts require a transformation of thinking and once acquired there is no going back. Threshold concepts can be discipline specific, such as the concept of 
opportunity cost in economics (Meyer and Land 2003), or more generic such as critical thinking (Rattray 2017).

Thresholds may be crossed quite suddenly, but it is more likely that the transformation in thinking will take some time, particularly if the threshold involves coming to terms with 'troublesome knowledge' that is knowledge that is counter-intuitive, conceptually difficult or alien (Meyer and Land 2005). Knowledge may be troublesome because it requires a student to take on a new identity. This identity may be about becoming part of the community of scholars in a discipline and thinking like them. For example, to think like a historian means accepting that history of events is an opinion based on the best possible evidence: there are no historical 'facts' and knowledge is contingent, shifting as new sources emerge.

The term 'liminality' is widely used by Meyer and Land and means being in the threshold. This is where students are juggling new ideas and ways of thinking, but are insecure and uncertain. They are in the threshold but have not yet understood or assimilated the threshold concept and they oscillate between old ways of thinking and mimicking new ways (Meyer and Land 2005). Liminal or threshold space can be an uncomfortable place for learners, but it could be exhilarating and exciting too (Felton 2016).

There is evidence for threshold concepts and threshold crossing in research-based education and what are often termed research 'skills' are not merely mechanical, but involve thought processes. Kiley and Wisker (2009) reported that supervisors in a range of disciplines identified six significant conceptual challenges for doctoral students: Argument; Theorising; Framework; Knowledge creation; Analysis and interpretation; and Research paradigm. Their study draws upon supervisor reports of student difficulties and lacks the student perspective, but Timmermann et al. (2013) have gone further and used data from student writing and rewriting of research proposals to understand research development in the initial stages of the 
research process. They identified that undertaking a literature review to generate a hypothesis or question could be a threshold concept, and there could be more. It seems likely that threshold concepts would be encountered in undergraduate research and enquiry, and delays in development in one area might hold back development in other areas. So, for example, if students are unable to formulate sensible questions, then they will not be able to plan appropriate data collection. Getting 'stuck' in this way is likely to make research unappealing to students.

So, threshold concepts could explain why some students struggle when undertaking research and enquiry at all levels and may disengage from research activity. Although we would expect research to be 'messy' and emotionally challenging at times, there may be ways of supporting student research through integrated curriculum design.

\section{Integrated research throughlines}

Crossing thresholds and learning from undertaking research/enquiry is likely to require revisiting difficult concepts over time, but Taraban and Logue (2012) have questioned how much time students actually spend on research in content-based degrees, or in standard undergraduate research projects. Brew (2013) proposes an integrated model for developing undergraduate research skills and developing student autonomy in research. Spreading the research activity over the whole programme gives a possibility of scaffolding students from closed teacher supported questioning to open-ended questioning. Others argue that it is better to start students off early with open-ended projects to establish an early researcher mind-set (Healey and Jenkins 2009; Spronken-Smith and Walker 2010). 
But, in an integrated curriculum design without assessment of research skill development throughout a programme, it is difficult to identify and address any threshold concepts (Timmermann, et al. 2013). Fung's (2017) connected programme design model is not only about integrating research opportunities into the whole programme, but also allows for progressive assessment of research development in what she terms the research 'throughline'.

\section{Context of the study: research throughlines}

The Connected Curriculum at a UK research intensive university is an institution-wide strategic initiative to support and encourage a move from research-led teaching to distinctive research/enquiry-based education. The main drivers are twofold: to reduce the separation of teaching and research activity so that teaching excellence has parity with research excellence, and to provide students with opportunities to enrich their studies and future career opportunities (Fung and Carnell 2017).

A research throughline aims to provide a mechanism for integrating research into disciplinary programmes with varying degrees of modularity, and assessing student progress in research capability over time. It requires coherent programme design:

Each programme of study needs to be designed in such a way that students experience a connected sequence of learning activities that empower them, step by step, to apply the skills and dispositions needed to undertake investigations. (Fung 2017 p. 6.)

There are many ways in which a research throughline can be built into programmes and assessed. Examples from Fung (2017) include:

1. Creating a series of mandatory or connected option modules which empower students to undertake research and enquiry throughout their programme. 
2. A capstone assessment such as a dissertation that brings together work from several modules.

3. A long thin module that stretches from beginning to end resulting in a Showcase Portfolio that draws on 'best' outputs for summative assessment.

4. A single core assessment such as a portfolio that builds through connected modules or through academic tutorial system where students can reflect on their understanding of the discipline and their developing skills.

The emphasis here is on coherent programme design, but there is little guidance on identifying which research/enquiry skills are to be developed and at what level. Levy and Petrulis' (2012) framework locates an enquiry based learning in one of four quadrants of identifying, pursuing, producing and authoring depending on the degree of new knowledge being produced and student framing of the enquiry. Fung favours authoring because students are firmly in the driving seat of research and enquiry to formulate their own critical questions and create new knowledge rather than explore existing knowledge. However, the extent to which a detailed research development framework is needed - perhaps an undergraduate version of the Vitae skills framework- is worthy of consideration.

Furthermore, there is a danger here of a research throughline taking a narrow and deterministic view of programme design. Curricula are dynamic and constantly interpreted and re-interpreted by both teachers and learners (Kandiko and Blackmore 2012). So while a designer's intention might be to connect a series of research activities that develop a set of research skills, the activities may be perceived differently by different learners who might proceed at different rates.

\section{Curriculum design to integrate research skills development and assessment}


Fung's (2017) view of coherent programme design includes "enabling students to develop a clear picture or narrative of their overall learning journey and to analyse their personal progress and future goals." (p.55) But, it is naive to assume that students will simply acquire research skills through being given opportunities to engage in research/enquiry, even if there are multiple opportunities. There are two closely related considerations that are significant here. Firstly, there must be assessment where students engage with feedback on their research development. Engagement with feedback means that students can apply the feedback to future work, in other words this is feed forward (Hattie and Timperley 2007). For a research throughline, students must be able to apply feedback to new research activities in a cumulative approach.

Secondly, students in a liminal state when they encounter a research-related threshold concept will need supporting and motivating. Outcomes-based assessment with a focus on what has yet to be achieved could demotivate them. Hughes $(2011,2014,2017)$ has argued that an ipsative approach to feedback, where learners receive information on their progress from a comparison of current work with previous work, enables learners to develop at their own pace. Ipsative feedback can be more motivating than feedback on final products, especially for those who do not achieve highly in the more competitive environments. Rattray (2017) further proposes that setting up progressively linked assessments with ipsative feedback and support is helpful for students as they cross a threshold.

\section{Visibility of research skills and ipsative assessment}

I have the feeling, or the hope, that I am making progress each day. That is what makes me work, compelled to understand the core of life. (Quote from Alberto Giacometti in exhibition at Tate Modern 2017) 
These words from the sculptor Alberto Giacometti provide an insight into the powerful motivational effect of a feeling of making progress. Yet, unlike in sculpture, progress is not often visible to learners in higher education disciplines.

But, assessing development in research attribute or any personal learning gain across a programme is not straightforward. Any judgement of personal learning gain requires comparative information of student performance at two separated points in time. This is relatively straightforward for assessors if a test is repeated or when a draft assignment is compared with a final assignment (Hughes 2014). However, a study of ipsative feedback highlighted the difficulties of firstly, having access to an earlier student performance, and secondly, comparing two assessments that are not identical and may be testing different attributes (Hughes et al. 2014). Consistency of language use around research skills will be significant here so that students and assessors understand terms such as 'analysis' and 'criticality' in their disciplinary context. Furthermore, while ipsative feedback is not contentious, including ipsative marks for progress as part of a summative assessment is considered to be problematic by both students and assessors because those with lower outcomes can be rewarded for progress, and this might diminish the competitive advantage of higher achievers (Hughes 2014).

\section{A study of research skills development across a throughline}

I have argued above that in a programme design to integrate research activities there may be difficulties associated with identifying and recording research development over time which has implications for progressive assessment strategies. In addition, particularly if researching involves threshold concepts and troublesome knowledge, then timely support for students will need attention. 
To gain a greater understanding of how research skills develop in practice over a taught undergraduate/Masters programme, the following questions were prepared:

1. What are the challenges for integrating research development over a taught degree programme?

2. How far can different research throughline designs help in overcoming these challenges?

To address these questions, five programmes that employed different approaches to learning and assessment in a throughline of research were identified. The challenges of implementing a research throughline were explored from the perspective of programme leaders and/or key teaching staff.

\section{Selection of programmes to review}

Programmes were selected that had been named as having a research throughline- see Table

1. This was a purposeful selection to ensure that a range of disciplines and both undergraduate and postgraduate programmes were represented, but choice was limited by the small number of programmes that had been recognised through internal publications and website.

Table 1 Programmes in the study and curriculum design

\begin{tabular}{|l|l|}
\hline Programme & $\begin{array}{l}\text { Method of embedding a research } \\
\text { throughline }\end{array}$ \\
\hline BA/BSc Archaeology & A series of modules which empower \\
& students to undertake research and enquiry \\
\hline
\end{tabular}




\begin{tabular}{|l|l|}
\hline & $\begin{array}{l}\text { (through fieldwork) plus a core portfolio } \\
\text { that builds through connected modules. }\end{array}$ \\
\hline MSc Engineering degrees & Capstone research project supported by \\
research skills workshops.
\end{tabular}

\section{Data collection}

The study was influenced by the Action Research/Practitioner Research paradigm where the aim is to understand and develop professional practice (Coghlan and Brannick 2010; Costello 2011; Fox, et. al. 2013). Programme leaders and key staff in the research throughline design were contacted to arrange an interview with the aim of evaluating and improving the research throughline method. In the BA Archaeology and BSc Natural Sciences there were two interviewees interviewed together, but in the others a single programme representative was interviewed. 
The interviews were conducted by a colleague introduced as a Connected Curriculum Fellow and the interviews were informal and collegiate, but drew on a set of semi-structured questions. The interviewee-interviewer relationship is complex and the aim was to maximise rapport and frankness and minimise discomfort. The resulting technique was a hybrid of a professional development discussion and interview. Questions were information and opinion seeking, but discussion of professional issues as peers was also encouraged with the interviewer offering advice and her own perspective in a professional dialogue. Extension of interview data was gathered after sending participants a copy of the transcription using email discussion.

Interviews were transcribed to include some features of linguistic and discourse analysis (Fairclough 1995). Paralanguage (such as ums and you know) and interruptions/interjections were noted, but not included in the reporting apart from laughter, added in brackets, and hesitations were represented by a single dot because these can indicate speaker uncertainty in a statement.

\section{Ethics}

The study was granted institutional ethical approval. Interviewees were provided with an information sheet and consent form to sign. Because programmes were named, and many are well known as exemplars across the institution it is not possible to guarantee anonymity, although names of the then programme representatives were removed from the reporting. The participants were aware of this. Participants were also sent a copy of the transcript and ask to clarify any points or correct any errors and all responded. They were also offered the opportunity to remove any material from the transcript, although none of the interviewees did so. 
Interviews were subjected to a thematic analysis in several stages following Auerbach and Silverstein (2003). In the initial stages coding was performed on text selected for relevance and themes of challenges and uncertainties emerging from the data were captured. In the later stages the theoretical material was applied to interrogate the effectiveness of assessment throughlines. Possible affordances of the different programme designs for managing the challenges were also considered.

\section{Limitations of the study}

Such insider research has the disadvantage of informant bias (Mercer 2007), and here the interviewer and the participants might have vested interests in conforming to the Connected Curriculum methods and a consequence might be to minimise the challenges and emphasise the positives. A further complication was that that two of the programmes (BSc Natural Sciences and BA Education Studies) had not yet fully implemented a research throughline and this meant that some ideas presented were aspirational. Other stakeholders such as students were not consulted and so this will be a partial picture.

\section{The challenges for integrated research-based education}

Interviewees were well able to describe their research throughline and illustrate this with examples of activities and assessments. Two main methods of embedding a throughline emerged. Firstly, research can be embedded into core modules and that would usually culminate in a substantial piece of research at the end of the course such as a project or dissertation (Engineering, Biomedical Engineering and Archaeology programmes). Secondly, the research throughline might involve a parallel structure to the main programme through students belonging to disciplinary research communities or having tutorials outside the formally taught modules where they hone and develop their research skills alongside more experienced researchers (BEd. and BSc Nat. Sci). 
Three challenges were apparent in all or most of the programmes:

1) Conceptualising the disciplinary and generic research skills that will develop over the programme and identifying threshold concepts

2) Student and staff recording and assessment of the accumulation and enrichment of research skills

3) Supporting the research development and self-regulation of all students in preparation for a post-truth world and not only of those who may continue as researchers.

Each of these challenges is now considered.

\section{Conceptualising disciplinary and generic research skills}

With the exception of Archaeology, the participants could not identify a comprehensive list of research skills/attributes immediately on being asked, and the range of research skills were identified sporadically during the interview discussion, which suggests that research development is not systematically discussed with colleagues or students. Emerging lists included generic academic skills such as literature searching (MSc Eng., BSc Nat. Sci.), academic writing (BA Ed.), creating an argument (BA Arch.), being critical (BA Ed., BSc Nat. Sci.), analysis (BA Arch.), communicating ideas (all) as well as collaborative/team working (all). Although these are essential for research/enquiry, these skills can be developed in a wide range of classroom and assessment activities and not only as part of a research throughline.

Other skills identified were more specifically about research and were usually discipline specific and practical, such as computer modelling/programming (MSc Eng., BEng Biomed.), social science research methods (BA Ed.), project management (MSc Eng.), excavation skills (BA Arch.), problem solving (MSc Eng.), product design (BSc Biomed.), and laboratory 
techniques (MSc Eng.). Generating research questions was included in all programmes as would be expected.

Once the research skills have been defined, a research throughline should aim to develop and assess particularly the research skills (Fung 2017) alongside more generic academic skills. There were two ways in which research skills might develop throughout the programme: a) cumulatively by increasing the range of skills; or b) by advancing the level of a particular skill.

a) Developing new research skills and broadening the range was strongly linked to the year of a degree programme in Natural Sciences and Education:

In year one that's mostly developing their practical skills, in year two it's mostly developing the scientific computing and communication skills and year 3 they have to do a literature review so it has to be some critical review of literature (BSc Natural Sciences).

We have a new students' year one module called understanding education research so about being critical. In year two at the moment they have to take two research methods modules history and qualitative social sciences . . and then in year three they can take the dissertation. (BA Ed.)

Here new skills are introduced each year and this approach might fit well with a modular programme with clearly defined year cohorts. Critical reviewing of ideas is a potential threshold concept, but there is no assurance that if students get stuck at any point, then they will have opportunities for threshold crossing later. This is the kind of criticality that needs to be embedded in undergraduate curricula to prepare students to deal with 'alternative' facts in a post-truth world. 
b) In other programmes there was also a cautious sense of advancement over the degree. The Biomedical Engineering programme aimed to enable students to cope with greater openendedness of research topics and questions in keeping with Brew's (2013) model:

I think I would argue that the open endedness increases year by year (MEng/BEng Biomed.)

In Natural Sciences there was also a hint of aspiration for their new long-thin research module towards increasing the sophistication of generating research questions through a shift from naivety to having robustness:

One thing we've struggled with is the idea of people coming in and creating a research questions with their tutor or with their transition mentor or both in the first year of their arrival . then they start with the naïve version of that. They're first year students what does the world look like from here now? . One idea is that you then refine each year as their view becomes more sophisticated as they become more able scholars, more able researchers it becomes a harder edged thing. (BSc Natural Sciences)

Similarly, formulating research questions was considered to be difficult for Archaeology students, but by the end of the programme they should be able to pose their own questions:

One of the key things is . trying to get them to figure out how to frame questions as you go through and that's obviously something you ramp up over the years not necessarily expecting them to walk in being able to pose their own questions but we certainly hope by the time we've got to the dissertation . you shouldn't actually be having to (do it). (BA Arch.) 
From both of these accounts, asking suitable research questions appears to be a threshold concept that must be mastered by the end of the course. Students on the Archaeology BA/BSc were also expected to shift their epistemological stance over the programme by increasingly viewing data as incomplete and research findings speculative:

The first year essays are "yes archaeologists solve all the problems" (then) we're saying having told you all this . "well . it's kind of a bit more tricky and to think about doing it yourself actually there are a lot of . noisiness and messiness and dirtiness .." so we kind of problematize if you like .. so that then in the third year it's a big opportunity .. it's genuine research. (BA Arch.)

A paradigm shift from certainty of 'facts' to appreciating knowledge as contingent - an important dimension of criticality- was identified as one of Kiley and Wisker's (2009) threshold concepts, and the assumption here that this attribute will develop along with increasing student autonomy and maturity may be optimistic.

While the programme leaders had some idea of research skills and academic skills that students would be expected to develop in the throughline, and there was an expectation that students would develop from year to year as the remit of a student researcher became openended enquiry or 'genuine research', there was no mention of any overall research skills development framework even for the core components of a programme (although the archaeologists did produce a generic archaeology skills list which included research skills which could be the starting point of a framework). Without a formalised framework or clearly articulated research development expectations, it will be difficult for students to appreciate what they are gaining from research-based learning and develop the personal narratives and student self-regulation proposed by Fung (2017), and threshold concepts such as critical thinking may not be recognised. Furthermore, without developing confidence in their 
research/enquiry skills, students will not be able to interrogate knowledge that they will encounter in other contexts. This leads us to the second challenge concerning the assessment and recording of research development.

\section{Student and staff recording of the accumulation and enrichment of research skills}

Recording of research development was through student self-assessment, but even with tutor support there was concern about student engagement with research skills.

The natural scientists speculated that there might be some form of self -monitoring record in their planned long thin research module:

..there will be from the start various 'I can' statements . . but then loosely around those it will be 'I will develop skills in..' . 'I can use . the software package to model something' but it can also be: 'I can take on board different models from different fields and produce .. sample results'. (BSc Natural Science)

Self-assessment could also take the form of a portfolio of learning development (BA Arch, BA Ed.). However, in the BA Ed. because this was not accredited there was some doubt about all students engaging with a portfolio:

Some personal tutors have been having their students writing lots others haven't been able to get their students to write anything so we need to share different approaches to see what works going forward .. there's a long way to go. (BA Ed)

There was also uncertainty over enabling student research narratives from the Archaeologists, one of whom when asked what would tell students that they were succeeding with research skills replied with "That's a very good question". But, they continued to discuss a formal method for students to record research skills in tutorials so have clearly thought about this. 
We have progress meetings with their personal tutor each term . It will vary a bit depending on how the tutor does it but the form that they fill in which actually asks about . some aspects of field work and things like that but also on the reverse of it has various skills that we've identified and comments on how they feel they are doing .. so there is a bit of a sort of a progression process.

In Masters programmes or when there is a supervised project, students may be required to record milestones in preparation for their research as part of project management. For example in the MSc in Engineering:

When students select their project they are expected to have a very brief outline to show that they've understood what the project is about and then come up with a timeline with their work with their supervisor and that will be reviewed a couple of times throughout.

They expected that students would become aware of their learning through this project management process but the programme leader admitted that this might only apply to the better students:

I think the better students do (understand project management) but the weaker ones probably never realise that's what it's there for.

There was some indication of why it might be a challenge to motivate all students to document their development in research. In Archaeology, degree classification overruled recording progress in research skills (ipsative assessment):

They're calculating how to get $\mathrm{x} \%$ to get a first class degree ... "well actually your ability to synthesise, communicate make archaeology relevant should stand you in good very good stead for your interviews etc." "oh I suppose so but if I don't get the 
grade it's not worth it is it? " so it's really interesting there's this very clear tension there between . them really chasing that grade and wanting to play safe and our aspiration to actually (stretch them).

Research skill development is not formally assessed and is thus competing with work that more obviously contributes to the degree. One solution might be to give credit for learning gain (Hughes, 2017), but there was a hint of concern about the feasibility and desirability of measuring research skill development:

I suppose that's cos it's difficult to benchmark, people would say people would play the system .. how do you assess something like skills in September and how they evolve throughout? (MSc Eng.)

The overall picture is that recording research trajectories, whether by staff or students themselves, is difficult within traditional assessment where there is measurement of final outcomes. But, if students do not articulate and recognise their burgeoning abilities in critical questioning or judging evidence, they are unlikely to apply the skills in their future lives.

\section{Supporting the research development and self-regulation of all students in preparation for} a post-truth world and not only of those who may continue as researchers

Programme leaders discussed the mechanisms in place to support students throughout their research development across the programme and indicated how they might identify students who are struggling with the many potential threshold concepts in research development. There was a variety of support systems, and a range of academic (teaching and research), technical staff involved: sometimes several sources of assistance being available to students. A common theme emerging was that identifying and helping students was not systematic, but depended on the commitment of personal tutors and/or research supervisors and other staff. 
In Biomedical Engineering, support for students was through group work scenarios that developed over the programme, but this was informal, tricky and reliant on vigilant tutors:

If . the work in that individual scenario would be assessed and the tutor will kind of have a feel as to whether that particular student isn't progressing, but we don't have a formal way of looking at progression from one to the other. I don't really know how we'd do that quite tricky . . I think within the small group you can manage that . informally fairly well . we do have a good sense of which students aren't engaging or who struggle with group work. (MEng/BEng Biomed.)

Tutors were not the only supporters. If attendance is a problem then a lab technician might pick this up:

What really works for us is a low-tech solution which is . (female name) she's our lab technician and she's in the lab for all the scenarios so the scenarios are generally run by different academics but she's there she's the person who knows the students and she's generally the person who warns us and says so and so hasn't been around for a couple of days so and so wasn't here for the last scenario either. (MEng/BEng Biomed.)

There was acceptance that support would be variable because:

. that is normally done at the supervisor level so if a supervisor feels a student is struggling hopefully they are a good enough member of staff that they will give that student the support that is required . there have been a few where the opposite does happen which is horrible and unfortunate but . you will get some academic members 
of staff who go . 'I've got five students . one of them's not engaged it's not worth my time quite frankly". (MSc Eng.)

In Education there was a hierarchy of staff who would intervene with struggling students depending on the severity of the issue:

We have kind of pick up systems where there's a series of different people with responsibilities. The seminar tutor will know the students directly because they're working in small groups of 14 or 15 they see them every week for 10 weeks and after will work with them throughout the year so that's the first port of call going up to module leaders to intervene if they're struggling, or (for those) who are not showing up refer them to the personal tutors when there's issues across modules. (BA Ed.)

The approach here is very much about student monitoring, particularly engagement and attendance, rather than students seeking help when they are in a liminal state.

By contrast, in Archaeology students had a range of people to turn to with an 'open door' policy:

The personal tutor has a role in progress and many become the main supporter but the students have a range of other ways. (Interviewee 1)

That works for the department as quite open door with approachable staff (Interviewee 2)

There was also more evidence here of a systematic approach to student academic monitoring that presumably includes research activity. Staff meetings are held after individual tutorials in which every student is discussed drawing on the personal tutor reports and student marks: 
We catch that (student stress and mental well-being issues) partly by progress (at) these tutorial meetings .. that is actually linked to a progress system so actually after that meeting . we have a staff meeting which is purely looking at student progress where we go through every student and identify how they are doing · particularly if there is a problem (BA Arch. Interviewee 2)

Having a range of staff to support and monitor student progress in research was possible in the Archaeology programme because the research throughline was embedded in several linked modules. Even so, they recognised the variability of tutors particularly in relation to academic rather than pastoral support:

I suspect that maybe our personal tutors are very aware to look out for students who've got problems and marginally less aware that even when there are students who don't have problems there is still work that you can do around academic progress in the intellectual sense. We no doubt have got personal tutors who do that well . (but) that might be an area of slight unevenness. (BA Arch. Interviewee 1)

Apart from the 'approachable staff' in Archaeology, the overwhelming approach to student monitoring and support is left to a range of tutors and laboratory staff and seems to be reliant on these staff having the necessary expertise, time and volition to help particularly struggling students with research and enquiry projects. Yet, if these students become disheartened by research and enquiry then this may discourage them from evaluating spurious claims to 'truth' when they leave university. 
However, belonging to research communities that include doctoral researchers was also important for the scientists (these were not mentioned in Education) who made use of doctoral students to provide this community support. The Natural Sciences team reflected that $\mathrm{PhD}$ students would provide the main support but had not yet considered the details:

I guess it's going to be primarily through . the $\mathrm{PhD}$ students who are going to be in touch with them yes just imagining that now ... it reminds me of something I was thinking when I was talking earlier on that just how central these $\mathrm{PhD}$ students are going to be. (BSc Nat. Sci.)

Some students had opportunities for summer studentships with non-teaching staff with mutual benefits:

The way they (staff) are capitalising (on student research projects) is by offering some studentships into $(\mathrm{PhD})$ and then taking these students who are trained to do problem solving having them in their lab for the summer and then coming to me and saying "Wow these students you've got are really good aren't they?", "Yeah come and teach 'em" (laughter). We do like getting students publishing if we can and get their names on stuff. (MEng/BEng Biomed.)

However, these are the top students who are earmarked for a $\mathrm{PhD}$, and the laughter indicates that this is not typical teaching, supporting the Taraban and Logue (2012) premise that research experiences can be positive for the stronger students who are favoured by supervisors.

While strong students and those at Masters level may develop self-regulation, it seems that for most undergraduate students, the support they can expect is very much dependent on the supervisory willingness and experience of the staff or $\mathrm{PhD}$ students who are available to help. 
Monitoring of progress to catch those who might be falling through the net early as Hughes (2014) recommends is not a priority, and the support is reactive rather than proactive. Such uneven support is of particular concern where students encounter threshold concepts in undertaking research and while research capable students may gain valuable skills for life in a post-truth world, those who miss out may be poorly prepared.

\section{Conclusion taking research-based education into the future}

This study has demonstrated an enthusiasm for incorporating an effective research throughline in taught programmes. Although there were different curriculum designs, it is clearly not the design itself, but the processes that support the design that will enable students to develop as researchers. However, while research-based education is gaining ground for undergraduates, this study has indicated that there are some challenges to address.

Firstly, there is the difficulty of defining generic and disciplinary research skills that might apply within a programme. Research skills can be viewed as a subset of graduate learning outcomes and so are part of a wider challenge of defining generic learning outcomes for graduates (Coates and Lennon 2014). The programme representatives in this study did not easily articulate exactly which generic and discipline specific research skills they aimed to develop in their throughlines. Although there was evidence of development of new research skills in each of the programmes, and of raising the level of skills introduced early on in the programme, potential threshold concepts were unrecognised, and it was assumed that all students would progress. There was a lack of any research skills development framework that aims to be transformative for students such as the Vitae framework mentioned earlier or the researcher development framework from Australia (Willison and O'Regan, 2008). Research development intentions must clearly address critical thinking so that the expanding 
research capabilities of undergraduates can enable them to function critically in a post-truth society.

Secondly, progress in a research throughline needs to be visible to students through self and/or teacher assessment, and in this study research development was not systematically captured. Although students had opportunities to self-monitor and record research development, they may need motivation to do this through understanding the purpose of undertaking research and recognising personal learning gain (Hughes 2017). Using a portfolio, or writing a tutorial record with feedback or equivalent mechanism for ipsative selfrecording of development may help.

But, assessment and recording of research skills may have a low priority compared to assessment of core content. Hughes (2014) has argued that such ipsative assessment is readily overshadowed by final outcomes assessment. The programme representatives in this study did not refer to cumulative and explicit assessment of research skill development over the programme, and assumed that research capability assessment would contribute to a more general portfolio or be assessed in a separate research skills course/module (Biomedical Engineers have an assessed research skills course and the MSc in Engineering programmes are planning a research skills module). It was also recognised that not all students would be able and willing to reflect on skill development, and this might apply to better students while others may lose out - especially if the research development is included in a portfolio that is not formally assessed as part of the degree. Such problems limit the potential of researchbased education in preparing students for a future where they will need to use evidence and critical thinking to judge the quality of knowledge to avoid being swayed by popularist discourse. 
Thirdly, the study has indicated that mechanisms for student support in research development vary widely and advice is provided by a range of people including supervisors, personal tutors, doctoral students and laboratory technicians. However, these people may not have sufficient expertise in supporting research. Some may have expertise, but at doctoral or Masters level and not for undergraduates, and they may not identify threshold concepts for those new to research. Having an accessible research community is likely to be helpful to mitigate against supervisor/student relationship problems and to provide support for students in threshold crossing. However, the degree of movement towards self-regulation of research activity that is sometimes expected for postgraduates also needs consideration for undergraduates, both for the students themselves, and to motivate staff to prepare all students for the future and not only those already on an academic researcher trajectory.

In a post-truth society, research-based education has a potential role for transforming all students through developing their critical thinking and questioning skills. More research is certainly needed into this claim and to explore any assumption that transformation of thinking in learning situations will lead to transformed thinking in other aspects of life. As a necessary step for such future research, this study demonstrates how student research development can be undermined by unclear expectations and threshold concepts that are inadequately worked through. Addressing the three challenges outlined in this paper is fundamental; otherwise research activities may end up encouraging students to mimic research practice or disregard it altogether, rather than to participate in knowledge evaluation and knowledge production, leaving them vulnerable to persuasion by popular and unregulated discourse. This would indeed be a missed opportunity for higher education.

\section{Acknowledgements}

I would like to thank the Arena Centre, UCL for funding this study. 


\section{References}

Auerbach, C. and Silverstein, L. B. 2003. Qualitative Data: An Introduction to Coding and Analysis. New York: NYU Press.

Brew, A. 2013. "Understanding the scope of undergraduate research: a framework for curricular and pedagogical decision-making." Higher Education 66:603-618.

Brewer, G., Dewhurst, A.M. and Doran, D. 2012. "Undergraduate Research Projects: practices and perceptions." Psychology Learning and Teaching 11(2): 208-214.

Coates, H. and Lennon, M. C. 2014. Propelling the field: Insights, trends and concepts: In Higher Education Learning Outcomes Assessment: International Perspectives, ed. H. Coates, 295-312. Peter Lang: Frankwurt am Main.

Craney, C., McKay, T., Morris, J., Prigodich and de Groot, R. 2011. “Cross-Discipline Perceptions of the Undergraduate Research Experience." The Journal of Higher Education (82)1: 92-113.

Coghlan, D. and Brannick, T. 2010, 3rd Ed. Doing action research in your own organization. London: Sage.

Costello, P. 2011, 2nd Ed. Effective Action Research: Developing Reflective Thinking and Practice. London: Continuum International Publishing Group.

Fairclough, N. 1995. Critical Discourse Analysis: the critical study of language. London: Longman Group Limited.

Felton,P. 2016. On the Threshold with Students. In Threshold Concepts in Practice, ed R. Land, J. H.F. Meyer and M. T. Flanagan, 3-9. Rotterdam: Sense Publishers.

Fox, M., Martin, P. and Green, G. (2013) Doing Practitioner Research. London: Sage. 
Fung, D. 2017. A Connected Curriculum for Higher Education. London: UCL Press

Fung, D. and Carnell B. 2017. 2nd Ed. UCL Connected Curriculum: Enhancing

programmes of study. University College London, UK. Available

online:www.ucl.ac.uk/connectedcurriculum.

Harland, T. 2016. "Teaching to enhance research." Higher Education Research and Development 35(3):461-472.

Hattie, J. and Timperley, H. 2007. “ The Power of Feedback.” Review of Educational Research 779(1): 81-112.

Healey, M. and Jenkins, A. 2009. Developing Undergraduate Research and Enquiry. York: Higher Education Academy.

Hodge, A. (2010) Review of progress in implementing the recommendations of Sir Gareth Roberts, regarding employability and career development of PhD students and research staff Research Councils UK. Online at http://www.rcuk.ac.uk/documents/skills/IndependentReviewHodge-pdf/ (accessed November 2017)

Hughes, G. 2017. Introducing ipsative assessment and personal learning gain. In Ipsative Assessment and Personal Learning Gain: Exploring international case studies. ed, G. Hughes, 1-21. Basingstoke: Palgrave Macmillan.

Hughes, G. 2014. Ipsative Assessment: Motivation through marking progress. Basingstoke: Palgrave Macmillan. 
Hughes, G., Wood, E. and Kitagawa. K. 2014. "Use of self-referential (ipsative) feedback to motivate and guide distance learners." Open Learning: The Journal of Open, Distance and eLearning 29(1): 31-44.

Hughes, G. 2011. “Aiming for Personal Best: a Case for Introducing Ipsative Assessment in Higher Education.” Studies in Higher Education 36 (3): 353 - 367.

Kandiko, C. B. and Blackmore, P. 2012. The Networked Curriculum. In Strategic Curriculum Change: global trends in universities, ed. P. Blackmore and C.B. Kandiko, 3-20. Abingdon: Routledge.

Kiley, M. 2009. "Identifying threshold concepts and proposing strategies to support doctoral candidates." Innovations in Education and Teaching International 46(3): 293-304.

Kiley, M. and Wisker, G. 2009. Threshold concepts in research education and evidence of threshold crossing." Higher Education Research and Development 28 (4):431-441.

Levy, P. and Petrulis, R. 2012. "How do first year university students experience inquiry and research, and what are the implications for the practice of inquiry-based learning?" Studies in Higher Education 37 (1):85-101.

Ng, L.L. and Pemberton, J. 2013. "Research-based communities of practice in UK higher education." Studies in Higher Education 38(10):1522-1539.

Kiley, M. 2009. "Identifying threshold concepts and proposing strategies to support doctoral candidates.” Innovations in Education and Teaching International 46(3): 293-304.

Kiley, M. and Wisker, G. 2009. Threshold concepts in research education and evidence of threshold crossing." Higher Education Research and Development Vol. 28 (4):431-441. 
Land, R., Cousin, G., Meyer, H.F. and Davies, P. 2006. Implications of threshold concepts for course design and evaluation. In Overcoming Barriers to Student Understanding:

Threshold concepts and troublesome knowledge, ed. J. Meyer and R. Land, 195-205. London: Routledge.

Mercer, J. (2007) "The challenges of insider research in educational institutions: wielding a double-edged sword and resolving delicate dilemmas." Oxford Review of Education 33 (1): $1-17$.

Meyer, J. and Land, R. 2005. "Threshold concepts and troublesome knowledge (2):

Epistemological considerations and a conceptual framework for teaching and learning." Higher Education 49: 373-388.

Meyer, J. and Land, R. 2003. Threshold Concepts and Troublesome Knowledge: Linkages to Ways of Thinking and Practising within the Disciplines Enhancing Teaching-Learning Environments in Undergraduate Courses Project, Occasional Report 4. http://www.etl.tla.ed.ac.uk/docs/ETLreport4.pdf

Rattray, J. 2017. Assessing Liminality: The use of ipsative formative assessment during a postgraduate taught induction programme to support the development of criticality. In Ipsative Assessment and Personal Learning Gain: Exploring international case studies. ed, G. Hughes, 130-149. Basingstoke: Palgrave Macmillan.

Seymour, E., Hunter, A., Laursen, S. and DeAntoni, T. 2004. "Establishing the Benefits of Research Experiences for Undergraduates in the Sciences: First Findings from a Three-year Study." Science Education 88(4): 493-534. 
Speed, E. and Mannion, R. 2017. "The Rise of Post-truth Populism in Pluralist Liberal Democracies: Challenges for Health Policy." International Journal of Health Policy and Management 6(5): 249-251.

Spronken-Smith, R. and Walker, R. 2010. "Can inquiry-based learning strengthen the links between teaching and disciplinary research?" Studies in Higher Education 35:723-740.

Taraban, R. and Logue, E. 2012. "Academic Factors That Affect Undergraduate Research Experiences.” Journal of Educational Psychology 104 (2): 499-514.

Timmermann, B. C., Feldon, D., Maher, M., Strickland, D. and Gilmore, J. 2013. "Performance-based assessment of graduate student research skills: timing, trajectory, and potential thresholds." Studies in Higher Education 38(5): 693-710.

Vitae Researcher Development Framework 2011 https://www.vitae.ac.uk/vitaepublications/rdf-related/researcher-development-framework-rdf-vitae.pdf/view Accessed February 2018.

Willison, J. and O'Regan, K. 2008 The Researcher Skill Development Framework. Accessed from http://www.adelaide.edu.au/rsd2/framework/rsd7/ August 2018.

Waite S. and Davis B. 2006. Developing undergraduate research skills in a faculty of education: motivation through collaboration." Higher Education Research and Development 25 (4): 403-419. 